\title{
Inter-Group and Intra-Group Externalities of Two-Sided Markets in Electronic Commerce
}

\author{
Lixiang Li, Yueting Chai, Yi Liu
}

Department of Automation, Tsinghua University, Beijing, China.

Email: \{li-lx07, chaiy, yiliu\}@mail.tsinghua.edu.cn

Received November $11^{\text {th }}, 2010$; revised December $23^{\text {rd }}, 2010$, accepted December $24^{\text {th }}, 2010$.

\begin{abstract}
The e-marketplaces, which play an important role in facilitating transactions and aggregating information in electronic commerce, show positive inter-group externalities where one group's benefit from receiving a service depends on the number of the intermediary services consumed by the other group, and negative intra-group externalities where the surplus is destroyed because members within the group compete with each other. In this paper, with a different approach from the emerging two-sided markets theory and the traditional microeconomic theory, we analyze a monopolistic e-marketplace owned by a third-party firm by substituting the size of consumers with the number of intermediary services. Moreover, we pay close attention to solving the following problems: 1) When these inter-and intra-group externalities exist, are both the demand curves and the pricing strategies of intermediary services different from those of traditional goods? 2) How to price intermediary services to maximize profit in the e-marketplaces? 3) How do these network externalities affect the management strategy of platforms? Finally, we exemplify such analytical results as pricing strategies of platforms with managerial practice of electronic commerce.
\end{abstract}

Keywords: Electronic Commerce, E-Marketplace, Two-Sided Markets, Network Externalities

\section{Introduction}

During the last decade, many business-to-business (B2B) and customer-to-customer $(\mathrm{C} 2 \mathrm{C})$ e-marketplaces, such as ALibaba, GlobalSources, BuyerZone, eBay, and Taobao, continue to flourish, and are generating enormous volumes of trades. However, some famous commercial websites like Commerce One had gone into bankruptcy. One common feature of these platforms is that, besides trade services, they also provide such information services as industry news and economic policies, consulting services for management decisions, and other services. In fact, these information services can fascinate sellers and buyers and help the platform form a virtual community to disseminate new message. Thereafter, this fascinates more sellers and buyers. Furthermore, most of these e-commerce platforms usually provide free service for sellers or buyers. A principle problem facing platform owners is how to price trade services to maximize their profit in electronic commerce? How do network externalities affect the management strategy of platforms? Which economic theory explains these economic phenomena? In fact, many literatures in two-sided markets begin to speculate these problems, but there is few systematic research results in electronic commerce.

According to the emerging theory of two-sided markets, e-marketplaces are a typical two-sided market. Rochet and Tirole [1] strictly defined two-sided markets as ones in which the price structure affects the economic outcome (volume, profits, and welfare). Some markets fit this description: B2B e-marketplaces, credit cards, media markets, real-estate agents and shopping malls. Evans [2] provided more cases and discussion of such two-sided markets. In these markets, intermediaries or "platforms" enable interactions among distinct groups of agents and attempt to gain the two sides with rational price to each side. This interaction exhibits inter- and intra-group externality: 1) inter-group externalities, or indirect network externalities, as far as the benefit enjoyed by a member of one group increases with the number of members of the other group; 2) intra-group externalities, or competition externalities, as far as the benefit enjoyed by a member of a group decrease because members within the group compete with each other. For instance, industrial B2B e-marketplaces shares these characteristics: 1) the more services consumed by sellers in e-marketplaces, the 
higher the benefits for buyers connected with platforms, and vice versa; 2 ) sellers compete for the trade of buyers, and vice versa. Therefore, business strategies of intermediaries are shaped by inter- and intra-group externalities. In the presence of inter-group externalities, Caillaud and Jullien [3] put 'divide-and-conquer' strategies subsidizing the participation of one side (divide) and recovering the loss on the other side (conquer). Intra-group externalities, however, blur the picture.

This paper naturally relates to the very recent literature on two-sided markets, pioneered by Rochet and Tirole $[1,4]$, Caillaud and Jullien [3], and Armstrong [5,6], based on the theories of network externalities initiated by Katz and Shapiro [7]. Rochet and Tirole [1,4] emphasize the importance of relative price elasticity of demand on the two sides of the platform in determining its pricing structures with general approaches. Besides, most analyses apply to specific industries: payment systems [8,9], Internet-related intermediation [3], software and video games [10,11], media markets [12]. Jullien [13] and Rochet and Tirole [1] propose useful road maps to this flourishing literature. The main emphasis of these papers is on the effects of inter-group externalities on the design of pricing structures, the competition between platforms, multi-homing vs. single-homing decisions, platform ownership, exclusive contracts and so on. Intra-group externalities are either abstracted away or not central to the analysis. The paper closest in spirit to mine is Yoo et al. [14] and Belleflamme and Toulemonde [15]: they study how the two types of network externalities jointly shape intermediary strategies in two-sided markets. However, all this papers essentially consume that the number of intermediary services consumed by an agent is either one or zero, but not directly affected by the consumer's budget and platforms' prices. That is to say, these papers don't consider sellers' and buyers' decision problems to choose the consumption quantity of services, but simply focus on whether agents will connect with platforms. In our model the consumption choices with budget constraints play an important role, because they affect the demand and prices of services consumed by sellers and buyers and therefore profits and social welfare. Contributing to the recent two-sided market theory, we introduce a novel mechanism 1) that models an industrial e-marketplaces with the theory of consumer behavior and the theory of the firm, 2) that illustrates the shape of the demand curves of intermediary services in platforms joined by two-sided network externalities, 3) that deduces the optimal pricing strategies of intermediary services when the impact of inter- and intra-group externalities is significant, 4) that shows the impact of such parameters as network externalities on optimal prices.

The rest of this paper is arranged as follows. Firstly, we model e-marketplaces joined by inter- and intra-group externalities in Section II. Secondly, we analyze the impact of the parameters that define sellers and buyers on price levels in Section III. Finally, section IV concludes.

\section{Model}

There are a monopoly platform and two types of consumers: sellers and buyers (denoted 1 and 2 in turn). As can be seen in Figure 1, an agent of one group pays attention to the quantities of intermediation services consumed by agents of the other group and competition among members within the group.

For simplicity, suppose the quasi-linear utility function of a member of sellers or buyers is determined as follows: when the platform admits $m_{1}$ sellers and $m_{2}$ buyers, the quantities of the intermediary services consumed by the ith $\left(i=1,2, \cdots, m_{1}\right)$ group- 1 agent and the $j$ th $(j=1,2$, $\left.\cdots, m_{2}\right)$ group-2 agent are $x_{1 i}$ and $x_{2 j}$ separately, each consumer's problem of choosing her most preferred consumption level given service prices $\mathrm{p}_{1}$ or $\mathrm{p}_{2}$ and wealth levels $w_{1 i}$ or $w_{2 j}$ can be stated as the following utility maximization problems:

$$
\begin{aligned}
& \underset{x_{1 i}}{\operatorname{Max}_{1 i}}=x_{1 i}\left[b_{1} X_{2}-r_{1}\left(X_{1}-x_{1 i} / 2\right)+B_{1}\right]+y_{1 i} \\
& =x_{1 i}\left[b_{1} \sum_{j=1}^{n_{2}} x_{2 j}-r_{1}\left(\sum_{i=1}^{n_{1}} x_{1 i}-x_{1 i} / 2\right)+B_{1}\right]+y_{1 i} \\
& \text { s.t. } \quad p_{1} x_{1 i}+y_{1 i}=w_{1 i} \quad i=1, \cdots, m_{1} \\
& \operatorname{Max}_{x_{2 j}}=x_{2 j}\left[b_{2} X_{1}-r_{1}\left(X_{2}-x_{2 j} / 2\right)+B_{2}\right]+y_{2 j} \\
& =x_{2 j}\left[b_{2} \sum_{i=1}^{n_{1}} x_{1 i}-r_{2}\left(\sum_{j=1}^{n_{2}} x_{2 j}-x_{2 j} / 2\right)+B_{2}\right]+y_{2 j} \\
& \text { s.t. } \quad p_{2} x_{2 j}+y_{2 j}=w_{2 j} \quad j=1, \cdots, m_{2}
\end{aligned}
$$

where $X_{1}\left(X_{2}\right)$ is the aggregate demand of services to sellers (buyers), $y_{1 i}\left(y_{2 j}\right)$ is the budget surplus to a member of sellers (buyers). The parameter $B_{1}\left(B_{2}\right)$ describes the net fixed benefit, which equals information values minus usage costs to sellers (buyers) in the platform. The inter-group externality parameter $b_{1}\left(b_{2}\right)$ weighs the

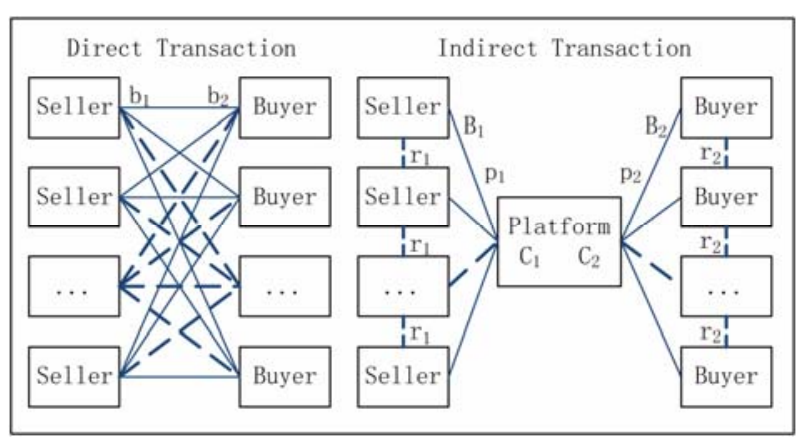

Figure 1. Inter- and intra-group externalities of e-marketplaces. 
benefit a member of sellers (buyers) enjoys from interacting with each member of sellers (buyers) because intermediaries save the transaction cost in direct transaction, and the intra-group externality parameter $r_{1}\left(r_{2}\right)$ weighs the loss a member of sellers (buyers) suffers from competing among members within the group each other. Generally, there are $b_{1}, b_{2}>r_{1}, r_{2}$ in e-marketplaces.

Using the first-order conditions of (1) and (2), we get the inverse demand functions to the two groups

$$
\begin{aligned}
& p_{1}=b_{1} X_{2}-r_{1} X_{1}+B_{1} \\
& p_{2}=b_{2} X_{1}-r_{2} X_{2}+B_{2}
\end{aligned}
$$

Equation (3) describes that the aggregate demand $X_{1}$ decreases with the price $p_{1}$ when $X_{2}$ is fixed, and the same to (4). It is consistent with the demand-price character of general goods or services. Simultaneous Equations (3) and (4) have a unique solution characterizing the demand $X_{1}$ and $X_{2}$ as functions of $\left(p_{1}, p_{2}\right)$ :

$$
\left\{\begin{array}{l}
X_{1}=\frac{r_{2} p_{1}+b_{1} p_{2}-r_{2} B_{1}-b_{1} B_{2}}{b_{1} b_{2}-r_{1} r_{2}} \\
X_{2}=\frac{b_{2} p_{1}+r_{1} p_{2}-b_{2} B_{1}-r_{1} B_{2}}{b_{1} b_{2}-r_{1} r_{2}}
\end{array}\right.
$$

Expression (5) shows that the aggregate demand $X_{1}\left(X_{2}\right)$ increases with the prices $\left(p_{1}, p_{2}\right)$ of services in the presence of inter-group and intra-group externalities. That is to say, the aggregate demand curve of services slopes upwards because network externalities make the two groups in the platform obtain more value from consumption of intermediary services when the network scale is more large.

From the cost side, we assume the monopoly platform will incur the marginal costs $C_{1}$ and $C_{2}$ for serving sellers and buyers respectively. Consequently, the platform's profit is equal to:

$$
\pi=\left(p_{1}-C_{1}\right) X_{1}+\left(p_{2}-C_{2}\right) X_{2}
$$

where the sunk cost is not considered implicitly.

Substituting (3) and (4) into (6), we obtain the firstorder conditions of the profit maximization problem:

$$
\left\{\begin{array}{l}
\partial \pi / \partial X_{1}=\left(b_{1}+b_{2}\right) X_{2}-2 r_{1} X_{1}+B_{1}-C_{1}=0 \\
\partial \pi / \partial X_{2}=\left(b_{1}+b_{2}\right) X_{1}-2 r_{2} X_{2}+B_{2}-C_{2}=0
\end{array}\right.
$$

From (7), the optimal aggregate consumption levels to the two groups are

$$
\left\{\begin{array}{l}
X_{1}^{*}=\frac{2 r_{2}\left(C_{1}-B_{1}\right)+\left(b_{1}+b_{2}\right)\left(C_{2}-B_{2}\right)}{\left(b_{1}+b_{2}\right)^{2}-4 r_{1} r_{2}} \\
X_{2}^{*}=\frac{\left(b_{1}+b_{2}\right)\left(C_{1}-B_{1}\right)+2 r_{1}\left(C_{2}-B_{2}\right)}{\left(b_{1}+b_{2}\right)^{2}-4 r_{1} r_{2}}
\end{array}\right.
$$

where $X_{1}^{*}>0$ and $X_{2}^{*}>0$ when the following conditions hold:

$$
\left\{\begin{array}{l}
2 r_{2}\left(C_{1}-B_{1}\right)+\left(b_{1}+b_{2}\right)\left(C_{2}-B_{2}\right)>0 \\
2 r_{1}\left(C_{2}-B_{2}\right)+\left(b_{1}+b_{2}\right)\left(C_{1}-B_{1}\right)>0
\end{array}\right.
$$

with $\left(b_{1}+b_{2}\right)^{2}>4 r_{1} r_{2}$ derived from $b_{1}>r_{1}$ and $b_{2}>r_{2}$.

We assume that expression (9) is satisfied for the following sections and the second-order conditions of the profit function for $\left(X_{1}, X_{2}\right)$ are also satisfied as follows:

$$
\left\{\begin{array}{l}
\partial^{2} \pi / \partial X_{1}^{2}=-2 r_{1} \leq 0, \quad \partial^{2} \pi / \partial X_{2}^{2}=-2 r_{2} \leq 0 \\
\left(\frac{\partial^{2} \pi}{\partial X_{1} \partial X_{2}}\right)^{2}-\frac{\partial^{2} \pi}{\partial X_{1}^{2}} \frac{\partial^{2} \pi}{\partial X_{2}^{2}}=\left(b_{1}+b_{2}\right)^{2}-4 r_{1} r_{2}>0
\end{array}\right.
$$

Substituting (8) into (3) and (4), we get the optimal prices to maximize the platform owner's profit:

$$
\left\{\begin{aligned}
p_{1}^{*}= & \frac{\left(b_{1}^{2}+b_{1} b_{2}-2 r_{1} r_{2}\right) C_{1}+\left(b_{2}^{2}+b_{1} b_{2}-2 r_{1} r_{2}\right) B_{1}}{\left(b_{1}+b_{2}\right)^{2}-4 r_{1} r_{2}} \\
& +\frac{\left(b_{1}-b_{2}\right) r_{1}\left(C_{2}-B_{2}\right)}{\left(b_{1}+b_{2}\right)^{2}-4 r_{1} r_{2}} \\
p_{2}^{*}= & \frac{\left(b_{2}^{2}+b_{1} b_{2}-2 r_{1} r_{2}\right) C_{2}+\left(b_{1}^{2}+b_{1} b_{2}-2 r_{1} r_{2}\right) B_{2}}{\left(b_{1}+b_{2}\right)^{2}-4 r_{1} r_{2}} \\
& +\frac{\left(b_{2}-b_{1}\right) r_{2}\left(C_{1}-B_{1}\right)}{\left(b_{1}+b_{2}\right)^{2}-4 r_{1} r_{2}}
\end{aligned}\right.
$$

These outcomes can be recorded as follows:

Proposition 1: The optimal prices $\left(p_{1}^{*}, p_{2}^{*}\right)$ and the optimal aggregate demands of intermediary services $\left(n_{1}^{*}, n_{2}^{*}\right)$, which maximize the platform owner's profit, are characterized by (11) and (8).

From (11), we can get that the optimal prices $\left(p_{1}^{*}, p_{2}^{*}\right)$ vary with different marginal service costs $\left(C_{1}, C_{2}\right)$. Intuitively, when the marginal cost for serving a group is higher, the price of intermediary services is expected to be higher in order to recover the loss of the platform. But, in e-marketplaces joined by inter- and intra-group network externalities, we deduce some unusual results about the relation between optimal prices and marginal costs for serving the two groups.

Proposition 2: In e-marketplaces connected with twosided network externalities, the price level to a group is lower than the marginal cost for serving it, whereas the price level to the other group is higher than the marginal cost for serving it.

Proof. With total optimal price level $p_{1}^{*}+p_{2}^{*}$, minus the total marginal cost for serving the two groups $C_{1}+C_{2}$, we obtain

$$
p_{1}^{*}+p_{2}^{*}-C_{1}-C_{2}=\left(r_{1}-b_{1}\right) X_{1}^{*}+\left(r_{2}-b_{2}\right) X_{2}^{*}<0
$$


Expression (12) shows that not every price level to a group is greater than the marginal cost for serving it. Moreover, the maximal profit of the platform is not negative, namely

$$
\pi^{*}=\left(p_{1}^{*}-C_{1}\right) X_{1}^{*}+\left(p_{2}^{*}-C_{2}\right) X_{2}^{*} \geq 0
$$

Expression (13) shows that not every price level to a group is smaller than the marginal cost for serving it. Therefore, there is either $\left(p_{1}^{*}<C_{1}, p_{2}^{*}>C_{2}\right)$ or $\left(p_{1}^{*}>C_{1}\right.$, $p_{2}^{*}<C_{2}$ ) within the monopoly platform joined by interand intra-group network externalities.

(Q.E.D.)

According to Proposition 2, the monopoly platform can recoup a loss or make a profit not by charging both higher prices, which exceed marginal costs to the two groups, but by charging a higher price to a group whereas providing price subsidy for the other group in e-marketplaces.

\section{Comparative Static Analysis}

From (11), we can find the relation between optimal prices and these parameters defined in this paper.

\subsection{Impact of Inter-Group Externalities on Service Prices}

Optimal prices of trade services vary with the magnitudes of inter-group network externalities to the two groups. The impact of positive inter-group externalities of both sellers and buyers on optimal service prices are stated as follows:

Proposition 3: When the magnitude of the inter-group network externalities to group 2 is not smaller than that to group $1\left(b_{2} \geq b_{1}\right)$, the service price to group $1 p_{1}^{*}$ becomes higher, but the service price to group $2 p_{2}^{*}$ becomes lower with the rise in the benefit of the inter-group externalities to group $1 b_{1}$. Oppositely, if the magnitude of the inter-group network externalities to group 2 is not bigger than that to group $1\left(b_{2} \leq b_{1}\right)$, the service price to group $2 p_{2}^{*}$ becomes higher, but the service price to group $1 p_{1}^{*}$ is lower with the rise in the benefit of the inter-group externalities to group $2 b_{2}$.

Proof. Many composite effects exist in e-marketplaces owing to several parameters, so the relation between the change of the optimal service price to each group and the relative change of inter-group network externalities $\left(b_{1}\right.$, $b_{2}$ ) is obscure. However, while the relative value between the inter-group externality parameters to the two groups is known, the changes of $p_{1}^{*}$ and $p_{2}^{*}$ become distinct. The first-order derivatives of optimal prices to the two groups, $p_{1}^{*}$ and $p_{2}^{*}$, on inter-group externality parameters $\left(b_{1}, b_{2}\right)$ in expression (11) are stated in expression (14). Since all $\partial p_{1}^{*} / \partial b_{1}$ terms are positive when $b_{2} \geq b_{1}$ and all $\partial p_{1}^{*} / \partial b_{2}$ terms are negative when $b_{2} \leq b_{1}$, $\partial p_{1}^{*} / \partial b_{1}$ is positive when $b_{2} \geq b_{1}$ and $\partial p_{1}^{*} / \partial b_{2}$ is negative when $b_{2} \leq b_{1}$.

$$
\begin{aligned}
& \frac{\partial p_{1}^{*}}{\partial b_{1}}=\frac{\left[b_{2}\left(b_{1}+b_{2}\right)^{2}-4 b_{1} r_{1} r_{2}\right]\left(C_{1}-B_{1}\right)}{\left[\left(b_{1}+b_{2}\right)^{2}-4 r_{1} r_{2}\right]^{2}} \\
& +\frac{r_{1}\left[\left(b_{1}+b_{2}\right)^{2}-4 r_{1} r_{2}+2\left(b_{2}^{2}-b_{1}^{2}\right)\right]\left(C_{2}-B_{2}\right)}{\left[\left(b_{1}+b_{2}\right)^{2}-4 r_{1} r_{2}\right]^{2}}>0, \frac{\partial p_{2}^{*}}{\partial b_{2}}>0 \\
& \frac{\partial p_{1}^{*}}{\partial b_{2}}=\frac{\left[4 b_{2} r_{1} r_{2}-b_{1}\left(b_{1}+b_{2}\right)^{2}\right]\left(C_{1}-B_{1}\right)}{\left[\left(b_{1}+b_{2}\right)^{2}-4 r_{1} r_{2}\right]^{2}} \\
& +\frac{r_{1}\left[4 r_{1} r_{2}-\left(b_{1}+b_{2}\right)^{2}-2\left(b_{1}^{2}-b_{2}^{2}\right)\right]\left(C_{2}-B_{2}\right)}{\left[\left(b_{1}+b_{2}\right)^{2}-4 r_{1} r_{2}\right]^{2}}<0, \frac{\partial p_{2}^{*}}{\partial b_{1}}<0
\end{aligned}
$$

(Q.E.D.)

$\partial p_{2}^{*} / \partial b_{2}$ is the same to $\partial p_{1}^{*} / \partial b_{1}$, whereas $\partial p_{2}^{*} / \partial b_{1}$ is the same to $\partial p_{1}^{*} / \partial b_{2}$; thus we only provide scenarios for $\partial p_{1}^{*} / \partial b_{1}$ and $\partial p_{1}^{*} / \partial b_{2}$. If the benefit of inter-group network externalities to a group is bigger, the utility of intermediary services to that group is bigger. Moreover, the service price to that group can be higher $\left(\partial p_{1}^{*} / \partial b_{1}>\right.$ $\left.0, \partial p_{2}^{*} / \partial b_{2}>0\right)$. However, inconceivably, the optimal service price to a group is lower while the benefit of inter-group network externalities to the other group is big$\operatorname{ger}\left(\partial p_{1}^{*} / \partial b_{2}<0, \partial p_{2}^{*} / \partial b_{1}<0\right)$.

\subsection{Impact of Intra-Group Externalities on Service Prices}

The relations between changes in optimal service prices and changes in different sizes of negative intra-group network externalities are showed as follows:

Proposition 4: If the benefit of the inter-group network externalities to group 2 is bigger than that to group $1\left(b_{2}>b_{1}\right)$, the price to group 1 (group 2) will be lower (higher) along with a rise in the benefits of the intra-group externalities $\left(r_{1}, r_{2}\right)$. Conversely, if the size of the inter-group network externalities to group 2 is less than that to group $1\left(b_{2}<b_{1}\right)$, the price to group 1 (group 2 ) will be higher (lower) along with a rise in the benefits of the intra-group externalities $\left(r_{1}, r_{2}\right)$.

Proof. The first derivatives of intra-group externality parameters $\left(r_{1}, r_{2}\right)$ on optimal prices of each group, $p_{1}^{*}$ and $p_{2}^{*}$ in expression (11) are provided in expression (15). If $b_{2}>b_{1}$ and (9) is satisfied, both $\partial p_{1}^{*} / \partial r_{1}$ and $\partial p_{1}^{*} / \partial r_{2}$ are negative, but both $\partial p_{2}^{*} / \partial r_{2}$ and $\partial p_{2}^{*} / \partial r_{1}$ are positive. Oppositely, if $b_{2}<b_{1}$ and (9) is satisfied, both $\partial p_{1}^{*} / \partial r_{1}$ and $\partial p_{1}^{*} / \partial r_{2}$ are positive, but both 
$\partial p_{2}^{*} / \partial r_{2}$ and $\partial p_{2}^{*} / \partial r_{1}$ are negative.

$$
\begin{aligned}
& \frac{\partial p_{1}^{*}}{\partial r_{1}}=\frac{\left(b_{1}^{2}-b_{2}^{2}\right)\left[2 r_{2}\left(C_{1}-B_{1}\right)+\left(b_{1}+b_{2}\right)\left(C_{2}-B_{2}\right)\right]}{\left[\left(b_{1}+b_{2}\right)^{2}-4 r_{1} r_{2}\right]^{2}} \\
& \frac{\partial p_{2}^{*}}{\partial r_{2}}=\frac{\left(b_{2}^{2}-b_{1}^{2}\right)\left[2 r_{1}\left(C_{2}-B_{2}\right)+\left(b_{1}+b_{2}\right)\left(C_{1}-B_{1}\right)\right]}{\left[\left(b_{1}+b_{2}\right)^{2}-4 r_{1} r_{2}\right]^{2}} \\
& \frac{\partial p_{1}^{*}}{\partial r_{2}}=\frac{2 r_{1}\left(b_{1}-b_{2}\right)\left[2 r_{1}\left(C_{2}-B_{2}\right)+\left(b_{1}+b_{2}\right)\left(C_{1}-B_{1}\right)\right]}{\left[\left(b_{1}+b_{2}\right)^{2}-4 r_{1} r_{2}\right]^{2}} \\
& \frac{\partial p_{2}^{*}}{\partial r_{1}}=\frac{2 r_{2}\left(b_{2}-b_{1}\right)\left[2 r_{2}\left(C_{1}-B_{1}\right)+\left(b_{1}+b_{2}\right)\left(C_{2}-B_{2}\right)\right]}{\left[\left(b_{1}+b_{2}\right)^{2}-4 r_{1} r_{2}\right]^{2}}
\end{aligned}
$$

\section{(Q.E.D.)}

We maybe hope that due to the bigger negative externalities among members within each group and the ultimate negative impact on the benefits of group 1 and group 2, the service prices to the two groups will at all time be lower. However, if $b_{2}>b_{1}$ (the attachment of group 1 is more worthy to group 2 than the attachment of group 2 to group 1), the service price to group 1 will be lower and the service price to group 2 will be higher when $r_{1}$ or $r_{2}$ becomes bigger. Similarly, if $b_{2}<b_{1}$ (the attachment of group 1 is less worthy to group 2 than the attachment of group 2 to group 1), the service price to group 1 will be higher and the service price to group 2 will be lower when $r_{1}$ or $r_{2}$ becomes bigger.

\subsection{Impact of Information Benefits on Service Prices}

The optimal price to each group is different with variation of the information benefits $\left(B_{1}, B_{2}\right)$. Instinctively, when the benefit of information services is greater, the expectation utility of the platform and the resulting price will also be higher. However, in some circumstances, we can find that the lower prices vary with the higher information benefits. The influence of information benefits to each group over the optimal prices is showed as follows.

Proposition 5: 1) If information benefit to group $1, B_{1}$ (group 2, $B_{2}$ ) becomes bigger, the service price charged to group $1 p_{1}^{*}$ (group 2, $p_{2}^{*}$ ), will be higher.

2) If the size of network externalities to group 2 (group 1 ) is bigger than that to group 1 (group 2), $b_{2}>b_{1}\left(b_{1}>\right.$ $b_{2}$ ), the service price charged to group $1, p_{1}^{*}$ (group 2 , $p_{2}^{*}$ ), will be higher when the information benefit to group $2, \mathrm{~B}_{2}$ (group $1, \mathrm{~B}_{1}$ ), becomes bigger,. Conversely, if the size of network externalities to group 2 (group 1 ) is smaller than that to group 1 (group 2), $b_{2}<b_{1}\left(b_{1}<b_{2}\right)$, the service price charged to group $1, p_{1}^{*}$ (group $2, p_{2}^{*}$ ), will be lower when the information benefit to group $2, B_{2}$ (group 1, $B_{1}$ ), becomes bigger in the same way.

Through the first derivatives of the information benefits $\left(b_{1}, b_{2}\right)$ on optimal service prices $p_{1}^{*}$ and $p_{2}^{*}$ in expression (11), we can easily prove the above proposition. If the information benefit to group 2 becomes bigger, the utility of the platform to group 2 will become bigger, and the service price to group 2 will also become higher $\left(\partial p_{2}^{*} / \partial B_{2}>0\right)$. Therefore, we hope that the service price to group 1 will also become higher simply because the bigger value of intermediary services to group 2 increases the benefit for group 1 with the indirect externality. However, inconceivably, the information benefits for group 2 is higher, the optimal price for group 1 is lower when $b_{2}<b_{1}$.

All results in the above propositions are summarized in Table 1.

\section{Managerial Applications}

In this paper, we have explored a general model of neutral e-marketplaces where the benefit to one group from inter-group externalities based upon the amount of services consumed by the other group and the loss to each group from negative intra-group externalities based upon competition among members within it. We conclude some useful results stated in the above propositions, which can help managers to determine the optimal pricing strategies of platforms connected with two-sided network externalities. Moreover, the significance of the relative size between the positive inter-group externalities to the two groups is emphasized in these proposi-

\begin{tabular}{|c|c|c|c|}
\hline $\begin{array}{l}\text { Parameter } \\
\text { (Increase) }\end{array}$ & $p_{1}^{*}$ & $p_{2}^{*}$ & Assumptions \\
\hline $\mathrm{b}_{1}$ & + & - & when $b_{1} \leq b_{2}$ \\
\hline $\mathrm{b}_{2}$ & - & + & when $b_{1} \geq b_{2}$ \\
\hline \multirow{2}{*}{$\mathrm{r}_{1}$} & - & + & when $b_{1}<b_{2}$ \\
\hline & + & - & when $b_{1}>b_{2}$ \\
\hline \multirow[b]{2}{*}{$r_{2}$} & - & + & when $b_{1}<b_{2}$ \\
\hline & + & - & when $b_{1}>b_{2}$ \\
\hline \multirow{2}{*}{$\mathrm{B}_{1}$} & + & - & when $b_{1}<b_{2}$ \\
\hline & + & + & when $b_{1}>b_{2}$ \\
\hline \multirow{2}{*}{$\mathrm{B}_{2}$} & + & + & when $b_{1}<b_{2}$ \\
\hline & - & + & when $b_{1}>b_{2}$ \\
\hline
\end{tabular}
tions. In practice, information about the perceptual character of these platforms may provide managers some

Table 1. Summary of propositions. 
useful clues in recognizing which inter-group externality is bigger.

Generally, a forward-auction e-commerce platform, i.e. seller's market, may have higher inter-group network externalities to sellers compared to a reverse-auction e-commerce platform, i.e. buyer's market. According to the above results, the service price to buyers may be very lower or zero in supplier-favored marketplaces contrasted with that in buyer-favored marketplaces. For example, such neutral platforms as alibaba.com, made-inchina.com, globalsources.com and taobao.com run buyer's market using posted prices or forward auctions. In comparison, the price charged to sellers will be lower in reverse-auction compared to that in forward-auction. For instance, FreeMarkets runs a buyer-favored B2B e-marketplace using reverse-auctions, most of the marketmaking costs are charged to buyers [16]. Most of platform's benefits come from sellers with charging membership fees or commissions, whereas these trade services are free for buyers. However, 315.com, which is a neutral B2B block trading e-marketplace in the oil industry, chemical industry, steel industry, plastics industry, and rubber industry, charges commissions according to the trading volume between buyers and sellers in the platforms.

\section{Conclusions}

In summary, our theoretical analyses enrich the emerging theory of two-sided markets with the introduction of negative intra-group externalities within members of the two groups. Based on our model, we derive the pricing strategy that an independent intermediary can use to maximize its profit. Based on our assumptions, the aggregation demand levels of participants in electronic markets as well as the prices charged from sellers and buyers in the electronic marketplace are dependent on the defined parameters of this paper.

For simplicity, we assume that equal prices are charged from all sellers and all buyers, whereas the cost of information services are all fixed costs that do not affect the pricing decisions of e-marketplaces as long as the total profit is positive. Also, we consider a monopolistic e-marketplace with a single-period model. Next, we hope to extend this analysis to a dynamic model with multiple periods. In future research, we will also analyze a duopoly model, which incorporates platform competition between intermediaries in electronic commerce.

\section{Acknowledgements}

This research is supported by the Key Projects in the National Science \& Technology Pillar Program in the
Eleventh Five-year Plan Period (Project Numbers: \# 2009BAH48B03).

\section{REFERENCES}

[1] J. Rochet and J. Tirole, "Two-Sided Markets: A Progress Report," Rand Journal of Economics, Vol. 37, No. 3, 2006, pp. 645-667.

doi:10.1111/j.1756-2171.2006.tb00036.x

[2] D. S. Evans, "The Antitrust Economics of Multi-Sided Platform Markets," Yale Journal on Regulation, Vol. 20, No. 2, 2003, pp. 325-381.

[3] B. Caillaud and B. Jullien, "Chicken \& Egg: Competition among Intermediation Service Providers," Rand Journal of Economics, Vol. 34, No. 2, 2003, pp. 309-328. doi: $10.2307 / 1593720$

[4] J. Rochet and J. Tirole, "Platform Competition in Two-Sided Market," Journal of the European Economic Association, Vol. 1, No. 4, 2003, pp. 990-1009. doi: $10.1162 / 154247603322493212$

[5] M. Armstrong, "Competition in Two-Sided Markets," Rand Journal of Economics, Vol. 37, No. 3, 2006, pp. 668-691. doi:10.1111/j.1756-2171.2006.tb00037.x

[6] M. Armstrong and J. Wrigh, "Two-Sided Markets, Competitive Bottlenecks and Exclusive Contracts," Economic Theory, Vol. 32, 2007, pp. 353-380. doi:10.1007/s00199-006-0114-6

[7] M. L. Katz and C. Shapiro, "Network Externalities, Competition, and Compatibility," American Economic Review, Vol. 75, No. 3, 1985, pp. 424-440.

[8] J. Wrigh, "Optimal Card Payment Systems," European Economic Review, Vol. 47, 2003, pp. 587-612. doi:10.1016/S0014-2921(02)00305-7

[9] J. Wrigh, "The Determinants of Optimal Interchange Fees in Payment Systems," Journal of Industrial Economics, Vol. 55, 2004, pp. 1-26. doi:10.1111/j.0022-1821.2004.00214.x

[10] G. G. Parker and M. W. V. Alstyne, "Two-Sided Network Effects: A Theory of Information Product Design," Management Science, Vol. 51, No. 10, October 2005, pp. 1494-1504. doi: $10.1287 / \mathrm{mnsc} .1050 .0400$

[11] A. Hagiu, "Pricing and Commitment by Two-Sided Platforms," Rand Journal of Economics, Vol. 37, No. 3, 2006, pp. 720-737. doi:10.1111/j.1756-2171.2006.tb00039.x

[12] M. Reisinger, L. Ressner and R. Schmidtke, "Two-Sided Markets with Pecuniary and Participation Externalities," Journal of Industrial Economics, Vol. LVII, No. 1, March 2009, pp. 1-26.

[13] B. Jullien, "Two-Sided Markets and Electronic Intermediaries," CESifo Economic Studies, Vol. 51, No. 2-3, 2005, pp. 233-260. doi:10.1093/cesifo/51.2-3.233

[14] B. Yoo, V. Choudhary and T. Mukhopadhyay, "A Model of Neutral B2B Intermediaries," Journal of Management Information Systems, Vol. 19, No. 3, 2002, pp. 1-12. 
[15] P. Belleflamme and E. Toulemonde. "Negative IntraGroup Externalities in Two-Sided Markets," International Economic Review, Vol. 50, No. 1, February 2009, pp. 245-272. doi:10.1111/j.1468-2354.2008.00529.x
[16] V. K. Rangan, "Free Markets Online," Harvard Case Study 9-598-109, Harvard University, Cambridge, February 1999 . 